\title{
CAPÍTULO 17: O TRANSPORTE PÚBLICO INCLUSIVO COMO POLÍTICA PÚBLICA DE EDUCAÇÃO INCLUSIVA EM RECIFE/PE
}

\section{CAPÍTULO 17: EL TRANSPORTE PÚBLICO INCLUSIVO COMO POLÍTICA PÚBLICA PARA LA EDUCACIÓN INCLUSIVA EN RECIFE / PE}

\section{CHAPTER 17: INCLUSIVE PUBLIC TRANSPORT AS PUBLIC POLICY FOR INCLUSIVE EDUCATION IN RECIFE / PE}

\begin{abstract}
Derek Luiz Alves dos Santos ${ }^{1}$; Islla Thairine da Silva Soares ${ }^{2}$; Laís Bezerra Nascimento de Lacerda ${ }^{3}$; Moisés da
\end{abstract} Silva Gomes ${ }^{4}$, José Luiz Alves ${ }^{5}$

DOI: https://doi.org/10.31692/978-65-88970-03-4.215-220

\section{INTRODUÇ̃̃̃O}

A educação no Brasil é um direito fundamental garantido pela lei maior do país, a Constituição Federal de 1988 - CF/88. (BRASIL, 1988) Mas para assegurar a efetividade do que a lei prescreve, o Estado precisa se utilizar de estratégias que consigam abarcar a universalidade dos indivíduos, com todas as peculiaridades e demandas diferentes. Nesse cenário, ganha destaque o conceito e as práticas da educação inclusiva, que permite que as pessoas exerçam seu papel de cidadão efetivamente e que sejam inseridas na sociedade independente de suas limitações, sem discriminação ou exclusão.

Dessa forma, destacar as políticas públicas inclusivas na área da educação, torna-se relevante, haja vista que as ações realizadas são passíveis de avaliação. Assim é possível acompanhar a evolução dos benefícios conquistados para o setor educacional, sobretudo quanto à educação especial.

De tal modo, objetiva-se destacar a função social das políticas públicas em uma esfera micro: a local. Tais políticas que partem do âmbito municipal enfrentam desafios em sua arena de decisão em priorizar determinadas ações em detrimento de outras, principalmente, devido ao restrito aporte de recursos financeiros para solucionar a diversidade de problemas sociais apontados. Contudo, cabe trazer à tona que a definição das prioridades deve ser levada não apenas por critérios de custos, mas, sobretudo pelos benefícios que atingirão os mais excluídos, principalmente quando se trata de pessoas com necessidades especiais.

Foram levantadas as principais ações executadas pela Prefeitura do Recife no Estado

\footnotetext{
1 Mestre em GDLS pela Universidade de Pernambuco - UPE, Instituto Federal de Pernambuco - IFPE, derek.alves@,recife.ifpe.edu.br

${ }^{2}$ Mestranda em GDLS, Universidade de Pernambuco - UPE, islla soares@hotmail.com

${ }^{3}$ Mestra em GDLS, Universidade de Pernambuco - UPE, laisbnlacerda@gmail.com

${ }^{4}$ Mestre em GDLS, Universidade de Pernambuco - UPE, msgo7@hotmail.com

${ }^{5}$ Doutor, Professor da Universidade de Pernambuco - UPE, luiz.alves@upe.br
} 
de Pernambuco, em termos de políticas públicas, que visem garantir o acesso à escola e o direito à aprendizagem no município com foco no transporte educacional inclusivo na cidade, uma vez que ele é primordial para a promoção do acesso igualitário e frequência de estudantes deficientes, ao contexto do dia a dia escolar.

\section{FUNDAMENTAÇÃO TEÓRICA}

"A educação inclusiva é um sistema de educação de ensino em que todos os alunos com necessidades educacionais especiais, incluindo alunos com deficiência, frequentam escolas comuns, da rede pública ou privada, com colegas sem deficiências”. (GIL, 2005, p.12) Nesta mesma perspectiva, Sanches e Teodoro (2007) ratificaram que a educação inclusiva é a capacidade de aprender em sala de aula com um conjunto de indivíduos heterogêneos. Apesar do desafio, a educação inclusiva permite que a educação seja oferecida a todos de forma igualitária.

O movimento mundial pela inclusão educacional se inicia com a Declaração Universal dos Direitos Humanos de 1948 e estabelece em seu art. 26, $\S 1^{\circ}$, que todas as pessoas têm direito a instrução gratuita nos graus elementares e fundamentais. Define ainda que essas instruções sejam obrigatórias e acessíveis a todos. (ONU, 1948)

No Brasil, somente com a promulgação da Lei de Diretrizes e Bases na Educação LDB, Lei 4.024/61 é que a educação inclusiva fez parte como componente do nosso sistema educacional. E no art. 88 da LDB, a normativa enquadra a educação de excepcionais, no sistema geral da educação. (BRASIL, 1961) Porém, foi a partir da promulgação da CF/88, conhecida como "Constituição Cidadã" que este tema ganhou maior impulso. A CF/88. brindou, em seu art. $3^{\circ}$, inciso IX, o direito ao bem-estar de todos sem preconceito ou qualquer outra forma de discriminação. Em seu Art. 208, inciso III, a norma legal ordena o atendimento educacional especializado aos portadores de deficiências na rede regular de ensino. (BRASIL, 1988)

A educação inclusiva teve um novo impulso quando o Brasil adotou algumas diretrizes e princípios da Declaração de Salamanca, realizada na Espanha em 1994, onde foram tratadas políticas de inclusão no ensino regular aos alunos com necessidades especiais. (UNESCO, 1994) Outra importante medida proposta foi a nova LDB, Lei 9.394/96, que revogou a Lei 4.024/61 e conferiu um aumento gradual dos alunos com necessidades especiais nas instituições de ensino, pois estabelece que as escolas capacitem os professores regulares para elaborarem atividades inclusivas. (BRASIL, 1996).

Com a sanção da Política Nacional de Educação Especial em 2008, a legislação 
brasileira obteve mais um suporte para a inclusão de alunos especiais ao orientar o funcionamento e a organização da educação especial no sistema educacional brasileiro. (BRASIL, 2008) Todavia, somente no ano de 2015 é que foi promulgada a Lei Brasileira de Inclusão da Pessoa com Deficiência. A Lei 13.146 de 06 de julho de 2015 tem como base a convenção sobre os direitos das pessoas com deficiências. (BRASIL, 2015)

Em virtude disso, a Prefeitura do Recife sancionou leis e decretos direcionados a educação de pessoas com necessidades especiais. A Lei 15.555/1991 criou a Diretoria de Serviços Educacionais para acolhimento nas escolas da rede municipal, alunos com necessidades especiais, uma Coordenadoria de Ensino Especial a qual passou a atuar por intermédio do Núcleo de Atendimento Integrado - NAI (RECIFE, 1991).

Em 1999, a Prefeitura recifense sancionou a Lei 16.529/99, em que reconhece a linguagem brasileira de Sinais - Libras como um sistema linguístico no Município do Recife. (RECIFE, 1999) Ademais, buscando integrar as ações de políticas municipais dos direitos humanos com as demais políticas de inclusão, a Prefeitura da capital pernambucana sancionou a Lei 17.199/2006, criando a política municipal de inclusão da pessoa com deficiência. (RECIFE, 2006) Ainda em 2006, o Município instituiu pela Lei 17.247/06, o Conselho Municipal de Defesa dos Direitos da Pessoa com Deficiência. (RECIFE, 2006a)

\section{METODOLOGIA}

Na referida perspectiva, propõe-se uma pesquisa de natureza aplicada, uma vez que se busca gerar conhecimentos ora dirigidos à solução de problemas específicos; com abordagem quali-quanti, sendo assim classificada, por retratar números numa conjuntura estatística e, por conseguinte, também possibilitar uma análise com maior profundidade contextual.

Possui um enfoque exploratório-descritivo, uma vez que buscará aproximar-se do objeto na perspectiva de levantar as suas características, e descreve-las na tentativa de melhor conhecê-las e contextualiza-las.

A coleta de dados e informações se deu por levantamento documental bibliografia. A triagem se deu a partir da busca de artigos científicos realizada pela plataforma eletrônica Google Acadêmico, bem como pela busca na internet de reportagens e notícias, por meio do buscador Google, todas, relacionadas a referida temática. Ademais, fora visitada a página governamental da Prefeitura do Recife, a fim de obter-se acesso aos números gerais relacionados à ação específica: Transporte Escolar Inclusivo, para análise e discussão, bem como, análise documental. 


\section{RESULTADOS E DISCUSSÃO}

De acordo com os dados divulgados pela Prefeitura do Recife, entre os anos de 2012 e 2019 houve um aumento de 46,5\% no número de matrículas de alunos com deficiência, transtornos globais do desenvolvimento e altas habilidades ou superdotações na rede municipal de ensino, passando de 2.661 para 3.900 estudantes matriculados. (RECIFE, 2019a) Tal informação revela a relevância que a educação inclusiva vem ganhando ao longo do tempo.

Tanto a obrigatoriedade do cumprimento da legislação por parte do Estado quanto à tomada de consciência sobre a universalidade dos direitos por parte dos cidadãos, fez com que se desenvolvesse e estimulasse políticas públicas educacionais voltadas especificamente para esse grupo.

A representatividade dessa categoria em relação a toda a rede de ensino do Recife aumentou em 2019, a participação de estudantes inclusos em salas regulares fixou-se no respectivo período, em 4,3\%. (RECIFE, 2019a) O aumento gradual da parcela de alunos que necessitam de algum tipo de adaptação ou apoio no processo de aprendizagem ocasionou o desenvolvimento de ações dentro da política de educação inclusiva que atendam as diversas peculiaridades existentes dentre os incluídos.

Em relação ao Transporte Escolar Inclusivo (TEI), também se identificam dados positivos após a sua implementação. O programa foi lançado pela Prefeitura do Recife em fevereiro de 2009 para atender, nos três turnos, alunos com deficiência, utilizando seis Kombis terceirizadas para realizar os serviços. (BLOG BENGALA LEGAL, 2009) Antes, apenas pouco mais de 200 alunos eram contemplados com a política do TEI. Em fevereiro de 2019, o TEI passou a beneficiar 334 estudantes da rede municipal de ensino, por meio de veículos adaptados, sendo 18 micro-ônibus e sete vans. Com esse quantitativo, a fila de espera pelos alunos que solicitam o TEI e que se encaixam nos critérios requeridos foi encerrada. (RECIFE, 2019 e RECIFE, 2019a)

A totalidade no atendimento dos discentes que necessitam da política implementada demonstra a importância que a Prefeitura do Recife confere a ela. Além disso, permite que os alunos tenham o acesso à escola garantido, influenciando, inclusive, na diminuição da evasão entre essa parcela de estudantes.

\section{CONCLUSÕES}

O processo educativo brasileiro foi marcado por uma herança predominante de 
diferenciação no ensino regular, o qual privilegiava os detentores de capacidades intelectuais em detrimento daqueles com necessidades especiais. Todavia, a heterogeneidade no ensino foi motivada pelas práticas da educação inclusiva, pois, a partir delas se buscou uma proposta de políticas públicas cujas relações de dignidade e do direito a cidadania foram incluídas.

As medidas e decisões tomadas por meio das políticas públicas educacionais inclusivas no Recife apresentaram êxito, no que tange ao direito do aluno com dificuldades de locomoção em ter acesso ao ambiente escolar. O que significa que a preocupação em suprir as demandas dos alunos especiais está presente nas políticas, e que os ganhos gerados promovem o acesso a educação a esse grupo.

Cada ação específica, como a do Transporte Escolar Inclusivo, agrega valor ao conjunto de iniciativas que beneficiam esses estudantes e, portanto, contribuem para atender as suas demandas de forma geral. Assim, por considerar a complexidade do tema abordado, entende-se que o universo que envolve a educação inclusiva não se limita, envolvendo outras abordagens, como a formação dos professores, socialização das práticas docentes, utilização de recursos adequados ao ensino, formação da identidade dos alunos especiais, participação da família, dentre outras.

\section{REFERÊNCIAS}

BLOG BENGALA LEGAL. Transporte Escolar para Alunos com Deficiência em Recife. Diário do Recife. Publicado na sexta-feira, 6 de fevereiro de 2009. Disponível em: $<\mathrm{http}: / /$ www.bengalalegal.com/blog/?p=24>. Acesso em: 25 abril 2019.

BRASIL. Constituição (1988). Constituição da República Federativa do Brasil. Brasília, DF: Senado Federal: Centro Gráfico, 1988.

. Lei no 4.024, de 20 de dezembro de 1961. Fixa as diretrizes e bases na educação. Revogada pela Lei 9394 de 1996. Disponível em: $<$ http://www.planalto.gov.br/ccivil_03/leis/14024.htm> Acesso em: 25 julho 2020.

Lei no 9.394, de 23 de dezembro de 1996. Revogou a Lei 4.024/1961. Estabelece as diretrizes e bases da Educação Nacional. Disponível em: $<$ http://www.planalto.gov.br/ccivil_03/leis/L9394.htm\#art92>. Acesso em: 25 julho 2020.

. Lei $\mathbf{n}^{0}$ 13.146, de 06 de julho de 2015. Institui a Lei Brasileira de Inclusão da Pessoa com Deficiência. Disponível em: <http://www.planalto.gov.br/ccivil_03/_ato20152018/2015/lei/113146.htm>. Acesso em: 25 julho 2020.

. Ministério da Educação. Secretaria de Educação Especial. Política Nacional de Educação Especial na perspectiva da Educação Inclusiva. Brasília: MEC, 2008.

GIL, Marta. Educação Inclusiva: O que o Professor tem a ver com isso? Marta Gil (coord), 
São Paulo, 2005.

ORGANIZAÇÃO DAS NAÇÕES UNIDAS - ONU. Declaração Universal dos Direitos Humanos. 1948. Disponivel em: <https://nacoesunidas.org/direitoshumanos/declaracao/> Acesso em: 25 abril 2019.

ORGANIZAÇÃO DAS NAÇÕES UNIDAS PARA A EDUCAÇÃO, CIÊNCIA E CULTURA - UNESCO. Declaração de Salamanca sobre Princípios, Política e Práticas na Area das Necessidades Educativas Especiais. 1994. Disponível em: $<$ https://unesdoc.unesco.org/ark:/48223/pf0000139394>. Acesso em: 25 abril 2019.

RECIFE. Lei $\mathrm{n}^{\mathbf{0}}$ 15.555, de 20 de dezembro de 1991. Cria na estrutura administrativa da fundação guararapes diretoria de serviços educacionais, uma coordenadoria de ensino especial e dá outras providências. Disponível em: $<$ https://cmrecife.jusbrasil.com.br/legislacao/270733/lei-15555-91>. Acesso em: 25 julho 2020.

Lei no 16.529 de 05 de novembro de 1999. Reconhece, no âmbito territorial do município do recife, como sistema lingüístico, a língua brasileira de sinais - libras. Disponível em: <https://cm-recife.jusbrasil.com.br/legislacao/264659/lei-16529-99>. Acesso em: 25 julho 2020 .

Lei $n^{0} 17.199$ de 27 de abril de 2006. Institui no âmbito da cidade do recife a política municipal de inclusão da pessoa com deficiência. Disponível em: $<\mathrm{https} / / \mathrm{cm}-$ recife.jusbrasil.com.br/legislacao/257113/lei-17199-06>. Acesso em: 25 julho 2020.

Lei $\mathrm{n}^{\circ}$ 17.247, de 27 de agosto de 2006a. Institui o conselho municipal de defesa dos direitos da pessoa com deficiência - comud. Disponível em: $<\mathrm{https} / / \mathrm{cm}-$ recife.jusbrasil.com.br/legislacao/256111/lei-17247-06>. Acesso em: 25 julho 2020.

Prefeitura do Recife. Educação Inclusiva do Recife recebe reforço com novos equipamentos e profissionais. Portal da Educação, 2019. Disponível em $<$ http://www.portaldaeducacao.recife.pe.gov.br/educacaoespecial $>$. Acesso em: 25 julho 2020 .

deficiência. $\quad$ Notícias, 2019a. $\quad$ Disponível $\quad$ em: $<$ http://www2.recife.pe.gov.br/noticias/18/02/2019/prefeitura-do-recife-reforca-apoio-alunoscom-deficiencia>. Acesso em: 25 julho 2020.

SANCHES, Isabel; TEODORO, António. Procurando indicadores de educação inclusiva: as práticas dos professores de apoio educativo. Rev. Port. de Educação, Braga, v. 20, n. 2, p. 105-149, 2007. Disponível em

$<$ http://www.scielo.mec.pt/scielo.php?script=sci_arttext\&pid=S087191872007000200005\&ln $\mathrm{g}=\mathrm{pt \& nrm}=$ iso $>$. Acesso em: 25 abril 2019. 